\title{
A contribuição dos estudos culturais para a abordagem da publicidade: processos de comunicação persuasiva e as noções "articulação" e "fluxo"1
}

\author{
Elisa Reinhardt Piedras² \\ UCPel \\ elisapiedras@hotmail.com \\ Nilda Jacks 3 \\ UFRGS \\ njacks@terra.com.br
}

\begin{abstract}
Resumo: Reconhecida por sua adequação para a abordagem da comunicação a partir da cultura, a perspectiva dos estudos culturais, em suas diversas vertentes, fornece subsídios para a discussão do processo comunicativo, suas práticas e formas simbólicas. Estas possibilidades viabilizam a proposta de uma lógica-metodológica alternativa para pesquisar a publicidade, entendida como um processo comunicativo constitutivo de certas práticas culturais e não como mero instrumental mercadológico, superando as análises parciais e dicotômicas de grande parte da pesquisas sobre esse tema. Através das noções de "articulação" (HALL, 1980) e "fluxo" (WILLIAMS, 1975), mapeamos as relações da publicidade com seu contexto, deciframos sua ambígua configuração contemporânea, a abordamos a lógica contraditória entre as práticas de produção, as práticas de recepção e o fluxo de anúncios publicitários.
\end{abstract}

${ }^{1}$ Artigo construído a partir da dissertação de mestrado intitulada "A articulação da publicidade com o mundo social: a constituição do fluxo publicitário nas práticas de produção e de recepção", de autoria de Elisa Piedras sob a orientação de Nilda Jacks / Programa de PósGraduação em Comunicação e Informação da UFRGS, defendida em março de 2005, Porto Alegre.

${ }^{2}$ Mestre em Comunicação e Informação, professora da Escola de Comunicação Social da UCPel, doutoranda em Comunicação na PUCRS.

3 Professora do PPGCOM/ UFRGS, pós- doutorado na Copenhagen University (1999) e na Universidade Nacional da Colômbia (em curso). 
Palavras-chave: estudos culturais; publicidade e propaganda; articulação.

Resumen: Reconhecida por sua adequação para a abordagem da comunicação a partir da cultura, a perspectiva dos estudos culturais, em suas diversas vertentes, fornece subsídios para a discussão do processo comunicativo, suas práticas e formas simbólicas. Estas possibilidades viabilizam a proposta de uma lógica-metodológica alternativa para pesquisar a publicidade, entendida como um processo comunicativo constitutivo de certas práticas culturais e não como mero instrumental mercadológico, superando as análises parciais e dicotômicas de grande parte da pesquisas sobre esse tema. Através das noções de "articulação" (HALL, 1980) e "fluxo" (WILLIAMS, 1975), mapeamos as relações da publicidade com seu contexto, deciframos sua ambígua configuração contemporânea, a abordamos a lógica contraditória entre as práticas de produção, as práticas de recepção e o fluxo de anúncios publicitários.

Asociaciones: estudos culturais; publicidade e propaganda; articulação.

Abstract: Recognized for its suitability to the study of communication from a cultural standpoint, the cultural studies perspective, in its different approaches, subsidizes a debate of the communication process, its practices and its symbolic forms. These possibilities allow the proposition of alternative methodological logics for the study of advertising - understood as a communication process which is part of certain cultural practices, not solely as a marketing tool -, which overcome the incomplete or dichotomous analysis in most of the studies on the subject. Based on the concepts of "articulation" (HALL, 1980) and "flow" (WILLIAMS, 1975), we map the interrelationships between advertising and its context, deciphering its ambiguous contemporary form and tackling the conflicting logics between the production practices, audience practices and flow of advertisements.

Key words: Cultural Studies, advertising, articulation

Resume: Reconnue par son adéquation pour travailler la communication d'après la culture, la perspective des études culturels, dans ses plusieurs lignes, donne des traces pour le débat sur le processus communicatif, ses pratiques et ses formes symboliques.Cettes possibilités rendrent possible la proposition d'une lógique-methodologique nouvelle pour rechercher la publicité, comprise comme un processus comunicatif qui fait partie des pratiques culturelles et pas comme un simple outil mercadologique. On propose rejoindre les analyses parcielles et dichotomiques de la plus grade partie des recherches sur c sujet. À travers les notions de " articulation » (HALL, 1980) et "flux » (WILLIAMS, 1975), on dessine les rapports entre la publicité et son contexte, on déchiffre sa configuration ambigüe contemporaine, et on étudie la logique contraditoire entre les pratiques de production, les pratiques de reception et le fux des annonces publicitaires.

Mots-clé: études culturels; publicité et propagande; articulation. 


\section{Introdução à temática da publicidade}

A publicidade é uma forma de comunicação caracterizada pela persuasão. Diferentemente da propaganda, que se ocupa da divulgação de idéias e pessoas, a publicidade 4 se dedica à divulgação de produtos e serviços, daí sua vinculação estrita com o modo de produção capitalista, o mercado e a cultura de consumo.

Como objeto de estudo, ela pode ser observada desde diferentes perspectivas, as quais configuram o seu entendimento. Se, de um lado, a publicidade pode ser reduzida a uma mensagem com a função de produzir e divulgar informações para vender bens, de outro, ela pode ser entendida como um processo comunicativo, cujas mensagens persuasivas são produzidas e recebidas em contextos contraditórios, implicados tanto pelo sistema hegemônico da estrutura econômica, quanto pelas práticas culturais dos sujeitos. Entre essas duas perspectivas, vemos transcorrer a evolução das abordagens da publicidade, como um reflexo das diferentes teorias utilizadas para pesquisar a comunicação.

Para pensar a publicidade como processo comunicativo constitutivo de certas práticas culturais, e não como mero instrumental mercadológico a serviço do capitalismo, partimos da relação entre a comunicação e a cultura. Apontamos os estudos culturais como uma perspectiva que viabiliza a construção de uma abordagem processual e cultural da publicidade, capaz de envolver as instâncias da produção, da recepção e de seus discursos, em um único cenário, que permite explorar suas inter-relações.

A percepção da contribuição dos estudos culturais para a pesquisa sobre a publicidade emerge da exploração de seu cenário no Brasil. Como afirmado em outro

\footnotetext{
4 Abordando historicamente a diferença entre a publicidade e a propaganda, Neusa Gomes (1998, p.240-242) explica que a necessidade da publicidade já existia na era do artesanato, mas se intensificou com a industrialização, a urbanização e a comunicação para as massas, sendo que, somente no século XIX instituiu-se o agenciamento de espaços comerciais. A propaganda, por outro lado, surgiu como um organismo responsável pela propagação da fé católica "em épocas onde o predomínio político e ideológico do catolicismo se sente ameaçado pelo nascimento e a rápida difusão das idéias luteranas".
} 
lugar (Jacks, 2001, p. 210), a temática da publicidade ainda é incipiente 5 e "[...] está longe de atender às necessidades sociais e culturais que o momento histórico requer". Nesse cenário, destaca-se a carência de abordagens que permitam uma análise da complexidade da publicidade em sua dimensão cultural, enquanto os enfoques polarizados, defensores ou denuncistas, repercutem em inúmeras pesquisas.

Tais enfoques são identificados por Umberto Eco e discutidos por José Marques de Melo no texto Nem apocalípticos, nem integrados, onde critica o maniqueísmo da "[...] atitude que tem dominado os intelectuais na avaliação dos processos modernos de comunicação, oscilando entre sua aprovação [...] e sua rejeição" (MELO, 1991, p. 1). O autor (idem, p. 9) reconhece que "[...] a publicidade reflete os valores existentes e respalda o ponto de vista dominante, [mas afirma que ela] [...] não pode ser tomada como responsável única pelas opiniões, normas e valores dominantes, nem tampouco ser absolvida de toda a responsabilidade por elas”. Afinal, antes de serem agentes positivos ou negativos, os meios de comunicação carregam "[...] as contradições das sociedades em que se inserem”. (p.7).

Assim, como resultado de uma tessitura de elementos integrados e apocalípticos, superando essa dicotomia criticada por Eco e assumida por Marques de Melo, vislumbramos uma brecha para a adoção de uma terceira tradição, que vem sendo chamada de cultural. Nesse sentido, Raymond Williams (1995, p. 320-336), pensador britânico dos estudos culturais, pode ser apontado como um precursor dessa abordagem, visto que, já na década de $60^{6}$, empreendeu uma análise social e histórica da publicidade, revelando que seu caráter comercial está vinculado a um sistema mágico de satisfações. Além disso, o autor discutiu o fato de que a

5 A pesquisa acadêmica brasileira sobre a publicidade produzida na década de 90 apresenta dados quantitativos sobre a carência de estudos dedicados a essa temática: "[...] dentre os 409 trabalhos defendidos entre 1992 e 1999 na PUC de São Paulo, somente oito tiveram como tema a publicidade/propaganda, dos quais sete estavam interessados em estudar a linguagem; na UNICAMP, somente um dentre 63; na UMESP, 23 entre 176; na USP, 32 dentre 402 [...]; na UFBA, quatro entre 53; na UFRJ, oito entre 402; na UNB, um entre 56; na UFMG, dois entre 22. Quanto aos programas localizados no sul do país - PUCRS, UNISINOS e UFRGS, o cenário não difere muito: dentre 54 trabalhos defendidos na UNISINOS somente cinco tiveram esta temática, estudados pela perspectiva da linguagem e da produção de sentido; na PUCRS, 10 dentre 103, e quanto à UFRGS, dentre 29 pesquisas nenhuma dedicou-se a este objeto" (JACKS, 2001).

6 O ensaio "Advertising: the magic system" foi publicado pela primeira vez em 1969. As notas foram tomadas da sua re-edição em: DURING, Simon (org.). The Culture Studies Reader. London: Routledge, 1995, p.320-336. 
publicidade, além de patrocinar outras instituições, "estendeu-se a áreas de valores sociais, econômicos e explicitamente políticos, como uma nova espécie de instituição cultural empresarial” (WILLIAMS, 1992, p. 53, tradução nossa).

A partir dessa ampliação do olhar sobre a publicidade, é possível compreender seu processo de comunicação (produção, mensagem e recepção) contextualizado historicamente na economia, na política e na cultura de determinada sociedade como forma de avaliar seu lugar no mundo contemporâneo. Nesse contexto, a publicidade coloca em relação práticas sociais distintas, como as de produção e de recepção, o que merece ser globalmente entendido pelos pesquisadores da área.

Assim, para além de abordagens maniqueístas e parciais da publicidade, que insistem em deslocá-la do mundo social, o avanço da pesquisa nesse campo exige esforços teóricos que viabilizem um tipo de análise ampla do tema, "na qual os fatores econômicos, sociais e culturais que são visivelmente relacionados, sejam contemplados", como propunha Williams (1995, p. 334, tradução nossa).

É necessário então, pensar a publicidade desde uma perspectiva que nos leve a considerar as ambigüidades e as contradições do seu processo comunicativo, superando a fragmentação das análises isoladas de anúncios e campanhas, de sua produção ou de sua recepção, de que tem se ocupado a maioria das pesquisas analisadas (PIEDRAS, 2005, p. 16-28). Nesse sentido, os estudos culturais fornecem uma "lógica metodológica" de exploração da publicidade sem determinismos econômicos ou idealismos culturais ${ }^{7}$, permitindo explorar sem maniqueísmos ${ }^{8}$ as relações correspondentes e contraditórias que envolvem a articulação das práticas de produção e de recepção, e da sua forma cultural.

\footnotetext{
7 O jamaicano Stuart Hall, numa tentativa de superar os determinismos econômicos e os idealismos culturais, propõe a noção de articulação para pensar os processos sociais. A discussão dessa proposta no âmbito da publicidade será apresentada posteriormente. 8 Martín-Barbero (2003, p.321), numa crítica à estrutura dualista ainda vigente em muitos estudos da comunicação, busca na história aquilo que as posições maniqueístas evitam: as ambigüidades.
} 


\section{Os estudos culturais como lógica - metodológica}

Nossa proposta é de que os subsídios fornecidos pelos estudos culturais, são menos procedimentos e técnicas do que uma lógica para estudar e mapear a relação entre a publicidade e o mundo social. Essa noção de metodologia como uma lógica de pesquisa decorre da reflexão de Luis Jesús Galindo Cáceres (1997), que afirma:

Para entender, o pesquisador requer um método de configuração que lhe permite distinguir níveis e complexidades de componentes e relações entre elementos. Em outras palavras, o pesquisador requer um ponto de vista lógico-metodológico, de uma teoria e de um programa metodológico. (GALINDO CÁCERES, 1997, p. 68, tradução nossa).

Nesse sentido, o ponto de vista lógico-metodológico desde o qual mapeamos a publicidade parte do deslocamento epistemológico proposto pelos estudos culturais. Martín-Barbero (2003) reivindica uma mudança do lugar onde as perguntas sobre comunicação são elaboradas, deslocando-as da dependência, da ideologia e dos meios $^{9}$, para o lugar da complexidade da experiência cotidiana e das mediações culturais. Isso reflete o peso epistemológico que atualmente é dado à cultura, ou seja, sua "posição em relação às questões de conhecimento e conceituação, em como [...] é usada para transformar nossa compreensão, explicação e modelos teóricos do mundo", segundo discute Stuart Hall (1997, p.16). Esse deslocamento nos leva a pensar as contradições da relação entre a comunicação e o mundo social, exigindo a superação das dicotomias que têm sido comentadas aqui (entre apocalípticos e integrados, radicais e liberais, estruturalistas e culturalistas), postura que precisa ser adotada para uma análise complexa da publicidade.

Partindo das práticas e das mediações culturais, podemos construir um mapa conceitual da publicidade que aponte possibilidades de análise de seu processo comunicativo na complexidade da experiência cotidiana, apontada, entre outros, por Mauro Wilton de Sousa (1999, p. 24-25), que consiste em "[...] situar desde as práticas culturais o eixo através do qual se analisa o processo comunicacional como um todo”. Através dessa estratégia, “[...] passa-se a reconhecer que as diferentes

\footnotetext{
9 Aqui Martín-Barbero (2003, p.28, p.290-94) se refere aos paradigmas hegemônicos dos estudos em comunicação dos anos 60 e 70, "ideologismo" e "informacionismo", que, nos anos 80 , já não davam conta do objeto de estudo da comunicação, que se transformava como toda a situação da América Latina. Nesse contexto, o autor reivindica a legitimidade de um novo paradigma, capaz de superar o "profundo desencontro entre método e situação".
} 
mediações sociais são o entorno cultural, a matriz de sentidos que alimenta o processo da recepção”, e percebe-se o receptor “[...] como sujeito e ator num processo mais amplo e complexo do que aquele que o circunscrevia apenas ao emissor e às tecnologias de suporte" (SOUSA, 1999, p. 24-25). Isso significa partir do cenário das dimensões do mundo social com as quais a publicidade se articula, e não somente dos meios de comunicação, explorando os contextos das práticas de recepção e produção que concretizam o processo comunicativo, deflagrado pela circulação dos anúncios.

Como a teoria que fundamenta nossa lógica-metodológica vem do aporte integral dos estudos culturais, isto nos permite abordar a publicidade a partir das relações entre a comunicação e a cultura, entre o texto e o contexto, considerando tanto as práticas como a estrutura e os aspectos micro e macro, articulados por ela no mundo social.

Se ainda quisermos explorar o programa metodológico, que é o mecanismo básico da organização e construção do sistema de conhecimento, há duas dimensões, como aponta Galindo Cáceres (1998, p. 11-12, tradução nossa): “o espaço conceitual e a árvore de busca”. Segundo o autor, a trajetória da pesquisa consiste na exploração de um espaço conceitual (o que conhecer) através de uma determinada árvore de busca (como conhecer). Em nosso caso, a trajetória da pesquisa envolve a exploração da temática da publicidade através da perspectiva dos estudos culturais, mapeando suas práticas (produção e recepção), formas (fluxo) e processos (de articulação da comunicação com o mundo social). Em termos conceituais, exploramos as noções de "articulação" e "fluxo" oferecidas pela perspectiva adotada, que são os operadores conceituais deste mapa sobre a publicidade, viabilizando o entendimento, respectivamente, de seu papel articulador de diferentes práticas no mundo social, e do fluxo como forma de seu discurso.

Essa estratégia metodológica de construir um mapa conceitual sobre a publicidade, ao passo que nos libera de optar por uma, dentre as várias técnicas usadas na análise empírica, nos permite propor um programa com base em algumas noções-chave: a de "articulação" trabalhada por Hall (1980) e a de "fluxo" por Williams (1974), complementadas pela discussão de Martín-Barbero (1990) sobre as mediações da socialidade, da ritualidade e da tecnicidade. 


\section{As noções de "articulação" e "fluxo"}

Apresentamos então brevemente as noções de "articulação" e de "fluxo", que viabilizam a exploração da publicidade como instância vinculadora dos níveis macro e micro do mundo social, objetivo ambicioso e nem por isso dispensável, que, apesar dos desafios, resiste como uma possibilidade de ampliarmos nosso olhar sobre o tema.

A noção de "articulação", apresentada por Stuart Hall em seus ensaios a partir da década de 80, foi desenvolvida como uma proposta para pensar as relações de determinação, problematizando as perspectivas deterministas econômicas ou idealistas culturais da análise social. Remetendo à vertente estruturalista ${ }^{10}$ dos estudos culturais, essa noção enfatiza a necessidade de pensar a cultura junto à ideologia, e as práticas a partir das condições determinadas pela estrutura. Com esta concepção, Hall propõe uma forma de pensar a relação entre as práticas e a estrutura em termos de uma dupla articulação, ou seja,

a estrutura - as condições dadas de existência, a estrutura das determinações em qualquer situação - pode também ser compreendida, de outra perspectiva, como simples resultado de práticas anteriores (...) anteriormente estruturadas. (...) A prática é a forma como uma estrutura é ativamente reproduzida. (HALL, 2003, p.167)

No nível teórico-metodológico, a articulação proposta por Hall é um "processo de criação de conexões" e caracterização das formações sociais pela contextualização do objeto de análise, como explica Jennifer Slack (1996, p.112-114, tradução nossa). A partir daí, pode-se explorar os distintos elementos que fazem parte da unidade analisada, bem como as relações entre eles, que co-determinam a sua presença social. Desse modo, a noção contribui para contextualizar a publicidade e pensá-la no âmbito de suas distintas práticas, explorando a vinculação delas com a estrutura social.

Quanto à noção de "fluxo", desenvolvida por Raymond Williams e apresentada em 1974 no livro Television: Technology and Cultural Form,

\footnotetext{
${ }^{10}$ Hall (2003, p.131-159) explica que, em decorrência da "articulação" complexa entre pensamento e realidade histórica, marcaram as bases da configuração da perspectiva: um paradigma dominante voltado para a cultura e a experiência humana, culturalista, e outro, estruturalista, vinculado às questões estruturais e da ideologia.
} 
caracteriza a natureza seqüencial e interrompida da programação no meio televisivo, principalmente nos sistemas comerciais. $\mathrm{O}$ autor assim a define:

Em todos os sistemas de radiodifusão desenvolvidos, a organização característica e, portanto, a característica da experiência, é uma seqüência ou 'fluxo'. Este fenômeno, do fluxo planejado, é então talvez a característica definidora da radiodifusão, simultaneamente como uma tecnologia e como uma forma cultural. Em todos os sistemas de comunicação, antes da radiodifusão, os itens essenciais eram discretos. (WILLIAMS, 1992, p.80-81, tradução nossa, grifo nosso).

Observando que a "distribuição de variadas formas de televisão com diferentes tipos de serviços”, característica deste meio, remete a uma definição mais móvel, Williams (1992, p.72-112, tradução nossa) partiu da experiência cotidiana dos sujeitos para abordar o fluxo televisivo. Entretanto, esta experiência não foi contemplada em estudos empíricos ${ }^{11}$, revelando a dificuldade de Williams em encontrar um método equivalente ao seu conceito, apontada por Lynn Spigel (1992, p.xxiv-xxvi, tradução nossa).

A solução para essa defasagem do método em relação à teoria é proposta por Klaus Jensen ${ }^{12}$ (1995), que aproxima a análise do fluxo às práticas de recepção. Segundo ele, para Williams "as emissões de televisão conduzem, por norma, a uma experiência concreta da audiência” e, nesse sentido, a noção contribui para a idéia de que a autonomia do telespectador é co-determinada pelas condições estruturais do fluxo midiático, o que exige a exploração dos aspectos da estrutura que condicionam esta experiência dita autônoma (JENSEN, 1995, p.109, tradução nossa). Jensen (1995, p.109-111, tradução nossa) propõe a distinção analítica de três aspectos do fluxo televisivo (o "fluxo do canal", o "fluxo do telespectador" e o "super-fluxo"), afirmando que ela "põe em destaque a necessidade de vários tipos de dados sobre os processos de recepção e para as análises comparativas da audiência e dos discursos dos meios de comunicação". Essa distinção é uma pista para propor a diferenciação entre dois tipos de "fluxo publicitário"- com relação às práticas de produção e de

\footnotetext{
${ }^{11}$ Em março de 1973 Williams (1992, p.72-112) empreendeu uma análise da programação televisiva em cinco canais, três britânicos e dois norte-americanos, através de um método focado na análise de textos, distribuição, justaposição de formas e sucessão de sons e imagens. 12 Utilizado em um estudo, com o objetivo de analisar empiricamente a televisão norteamericana e sua recepção (Jensen, 1995).
} 
recepção- , além de discutir a forma da seqüência do discurso da publicidade e sua relação com as práticas cotidianas a partir da noção de "fluxo".

Essas noções, principalmente a de "fluxo", recém começaram a ser incorporadas na pesquisa em comunicação no contexto brasileiro, embora na publicidade ainda não existam evidências de sua exploração. A pesquisa $A$ contribuição de Raymond Williams para a comunicação: os meios como tecnologia e forma cultural, de Anaí Camargo de Sousa (2004), é um exemplo da retomada da idéia de "fluxo" no campo da comunicação. No âmbito dos estudos de recepção, a presença da noção de "fluxo" em alguns artigos apresentados durante o ALAIC $2004^{13}$, permeando as discussões, também revelou o conceito como uma temática emergente.

O exercício de tentar re-construir nosso objeto de estudo por intermédio de conceitos desenvolvidos para abordar outros temas, como a "articulação" e o "fluxo", exige vigilância para que não se faça uma transposição inadequada de um objeto a outro. Então, após compreender os princípios daquelas noções, elas foram adotadas para pensar a publicidade em termos de seu trabalho como articuladora de práticas distintas e sua natureza configurada como fluxo.

Nesse exercício conceitual, foi crucial a contribuição de Martín-Barbero (1990, 2003) sobre as lógicas e as mediações das práticas de comunicação, o que permitiu explorar as particularidades das distintas práticas (de produção e recepção), sua relação com o fluxo (pela distinção entre o macro e o microfluxo) e a natureza contraditória de suas relações. Cabe destacar que essa vinculação das idéias do pensador latino-americano às discussões de Williams e Hall é mais um exemplo de como pode ser produtiva a relação entre as duas vertentes dos estudos culturais para pensar a comunicação, apontada por Escosteguy (2001).

13 ARAÚJO, Inesita Soares. Entre o Centro e a Periferia, há mais coisas do que supõe a nossa vã teoria: Proposta de uma matriz de análise dos fatores de mediação na prática comunicativa, no contexto de um modelo de comunicação para políticas públicas. In: CONGRESO LATINOAMERICANO DE INVESTIGADORES DE LA COMUNICACIÓN. Anais eletrônicos. GT Estudos de Recepção. ALAIC. La Plata, 2004. LA PASTINA, Antonio. Audience ethnographies: a media engagement approach. In: CONGRESO LATINOAMERICANO DE INVESTIGADORES DE LA COMUNICACIÓN. Anais eletrônicos. GT Estudos de Recepção. La Plata, 2004. 


\section{Mapeando a publicidade através dos estudos cultuais}

A partir destas idéias mapeamos os elementos de articulação da publicidade com o mundo social, seu contexto político-econômico-cultural, suas práticas, seu processo e sua forma de fluxo. Esse exercício teórico viabilizado pelos estudos culturais revela que, num movimento de constituição mútua entre a produção e a recepção, o fluxo publicitário articula produtos e universos simbólicos com as práticas cotidianas. Por fim, vemos que, entre a economia e a cultura, a publicidade influencia estruturalmente o consumo dos receptores e, simultaneamente, tem sua configuração influenciada pelas realidades, desejos e valores destes sujeitos.

A noção de "articulação" permite associar a publicidade com seu contexto social, ou seja, as condições econômicas do sistema capitalista, as políticas de regulamentação das atividades publicitárias, a cultura de consumo, as representações veiculadas pelos anúncios e as identidades dos receptores, entre outros fatores. A relação com todas essas dimensões do mundo social, confere à publicidade uma configuração multifacetada, já que é ao mesmo tempo uma instituição econômica de produção cultural, um sistema comercial e mágico, uma indústria e uma forma de arte (PIEDRAS, 2005, p.67-73).

Considerando este contexto e essa natureza ambígua da publicidade, voltamo-nos para as práticas articuladas por esse processo, partindo da distinção analítica entre a produção e a recepção, explorando depois as suas inter-relações, suas correspondências e contradições. Para isso, nos apropriamos do entendimento da lógica de produção e das lógicas de recepção, proposto por Jesús Martín-Barbero (2003, p.311-312), explorando-as em termos de modalidades de ação, respectivamente, estratégicas ou táticas, segundo a discussão de Michel de Certeau (1998, p.92).

As práticas de produção são institucionalizadas (nas agências publicitárias) e seguem um modo de ação estratégico. São o lugar da construção das mensagens publicitárias, com o objetivo claro de divulgar bens e serviços, estimulando a sua aquisição. A lógica segundo a qual essas práticas operam é singular e pode ser analisada pela exploração empírica nas agências publicitárias, de alguns dos seis dispositivos enumerados por Martín-Barbero (2003, p.311-312) como a "competência 
comunicativa", os "níveis e fases de decisão na produção do gênero", as "ideologias profissionais" e as "rotinas de produção" e as "estratégias de comercialização" (PIEDRAS, 2005, p.76-77).

Já as práticas de recepção não são institucionais, são do nível da socialidade e funcionam de modo tático. São o lugar da interpretação (leitura ou apropriação) das mensagens, não têm um objetivo claro e são permeadas pela subjetividade, podendo ir desde o interesse por informação e entretenimento ao consumo dos bens e serviços anunciados. As lógicas destas práticas são múltiplas, remetendo aos distintos usos que os sujeitos podem fazer das mensagens midiáticas, o que pode ser analisado empiricamente por dispositivos como o "habitus de classe" e a "competência cultural" (PIEDRAS, 2005, p.78-80), por exemplo.

$\mathrm{Na}$ "dupla articulação" entre essas práticas, a leitura e o consumo são codeterminados pelas demandas dos receptores e pelas ofertas da produção, além de condicionados pela estrutura econômico-político-cultural. Por isto, a força do sentido comercial predominante nos anúncios pela sua própria natureza, linguagem e formato, precisa ser observado nas análises ao lado dos sentidos alternativos produzidos nas práticas de recepção. Ou seja, as lógicas de recepção têm certa autonomia na situação da interação cotidiana com os meios e anúncios publicitários, mas não pode ser esquecido que estão articuladas com a estrutura social condicionante e com as práticas de produção das agências publicitárias (PIEDRAS, 2005, p.81-89).

Assim, apesar do processo publicitário ser constituído por ambas as práticas (de produção e de recepção), elas articulam-se com as forças sociais de modos distintos, o que remete a posições diferentes ocupadas por essas práticas na estrutura econômico-político-cultural, resultando em uma relação de diálogo assimétrico, que precisa ser considerado na sua análise.

A articulação das práticas à noção de "fluxo" permite explorar uma proposta analítica para a visualização da inter-relação daquelas práticas no processo comunicativo gerido pela publicidade, através da forma seqüencial e simultânea pela qual seus anúncios se apresentam no cotidiano. Assim como o "fluxo televisivo" de Williams, o que definimos como "fluxo publicitário" faz parte da experiência dos 
receptores que são interpelados por anúncios em jornais, rádios, televisão, outdoors, panfletos, cartazes, entre outros suportes (PIEDRAS, 2005, p.91-109).

Diante das dificuldades impostas por essa diversidade de suportes para propor um tratamento analítico do fluxo, recorremos a Jensen (1995, p.108, tradução nossa), para realizar a distinção em dois tipos de fluxo com relação às práticas: o macrofluxo produzido pela seqüência de anúncios de diversos anunciantes em vários suportes, e o microfluxo configurado pelos receptores em um determinado contexto a partir das ofertas macro. Enquanto o macrofluxo tem sua forma marcada por uma lógica estratégica, mediada pela institucionalidade e a tecnicidade, o microfluxo tem sua forma marcada pela lógica tática, mediada pela socialidade e pela ritualidade (PIEDRAS, 2005, p.110-117).

Além da distinção, sugerimos a exploração das inter-relações entre esses fluxos, verificando o potencial desta noção como operador analítico da vinculação da publicidade com o mundo social. Essa co-determinação do fluxo publicitário pelas ofertas da produção e dos meios, e pelas práticas dos receptores, não pressupõe uma simetria ou correspondência entre o macro e o microfluxo, mas sim distintos graus de autonomia dessas práticas, pois, apesar de os receptores contarem com alguma independência para construir o seu microfluxo, ela é circunscrita aos limites oferecidos pelo macrofluxo publicitário. Assim, as lógicas de recepção têm uma autonomia relativa na situação da interação com os meios e anúncios publicitários, mas, antes disso, estão articuladas com a estrutura das ofertas das práticas de produção das agências publicitárias (PIEDRAS, 2005, p.117).

\section{Considerações finais}

Após esse exercício de exploração teórica, podemos afirmar que os estudos culturais, reconhecidos pela sua adequação para a reflexão sobre a comunicação a partir da cultura, constituem uma perspectiva que nos permite adotar um enfoque cultural e processual da publicidade, superando os enfoques de caráter dicotômico e determinista.

Acreditamos que através do aporte integral dos estudos culturais chegamos a uma proposta teórica que parte das práticas, mas envolve as estruturas que as condicionam, relacionado-as de modo que revelem suas vinculações. Nesse sentido, 
as noções de "articulação" e de "fluxo" tornam possível identificar o papel vinculador da publicidade com as distintas dimensões do mundo social, explorando seu processo, suas práticas, a forma de seu discurso.

A contextualização sócio-econômico-cultural da publicidade e a discussão de sua natureza multifacetada oferecem pistas para uma abordagem de seu processo comunicativo como um todo articulado por práticas distintas. Isso permite que, mesmo naquelas análises que se detêm em uma ou outra dimensão do processo (os textos, por exemplo), seja considerada sua articulação com as demais (a produção e / ou a recepção), o que viabiliza a observação dos inúmeros fatores que fazem parte da produção de sentido do discurso publicitário.

Além disso, a discussão sobre as práticas de produção e de recepção aponta pistas sobre um cenário teórico para a sua análise empírica, tanto como instâncias distintas, quanto das suas inter-relações. Em ambas as possibilidades, as contradições internas de cada prática, e também aquelas resultantes da sua interrelação, são enfatizadas como um ponto crucial a ser observado em toda e qualquer pesquisa empírica.

Por fim, a proposta de adotar a noção de "fluxo" para analisar a forma do discurso publicitário veiculado pelos variados suportes e meios, oferece a possibilidade de explorar as particularidades dessa forma de comunicação, como a intertextualidade e a fragmentação. Além disso, a distinção analítica do macrofluxo instituído pela produção através dos meios - e microfluxo publicitário - configurado pelas práticas dos receptores - aponta para a viabilização de uma análise concreta da relação entre as práticas de recepção e o fluxo publicitário, considerando os condicionamentos da estrutura social e de produção.

O esforço empreendido nesta operação conceitual foi no sentido de problematizar o maior número possível de fatores que envolvem a análise da publicidade contemporânea, ressaltando especialmente as práticas de produção e recepção de seu discurso, e os vínculos que estabelecem com o mundo vivido em suas dimensões micro e macro social. 


\section{Referências:}

ARAÚJO, Inesita Soares. Entre o Centro e a Periferia, há mais coisas do que supõe a nossa vã teoria: Proposta de uma matriz de análise dos fatores de mediação na prática comunicativa, no contexto de um modelo de comunicação para políticas públicas. In: CONGRESO DE LA ASOCIACIÓN LATINOAMERICANA DE INVESTIGADORES DE LA COMUNICACIÓN, 7, 2004. Anais eletrônicos. GT Estudos de Recepção. La Plata: ALAIC, 2004. CD-ROM.

CERTEAU, Michel. A invenção do cotidiano - 1. artes do fazer. Rio de Janeiro: Vozes, 1998.

ECO, Humberto. Apocalípticos e Integrados. São Paulo: Perspectiva, 1976.

ESCOSTEGUY, Ana Carolina. Cartografias dos estudos culturais: uma versão latino-americana. Belo Horizonte: Autentica, 2001.

GALINDO CÁCERES, Luis Jesús. Sabor a ti: metodología cualitativa en investigación social. Xalapa, Universidad Veracruzana, 1997.

GOMES, Neusa. (coord.), CORRADI, A., CURY, L. A Dialética Conceitual da Publicidade e da Propaganda. In: Publicidade: Análise da Produção Publicitária e da Formação Profissional. São Paulo: Comunicação Publicitária ALAIC, 1998.

HALL, Stuart. A centralidade da cultura: notas sobre revoluções do nosso tempo. Educação e Realidade, Porto Alegre, vol.22, n.2, jul/dez 1997, p.15-45.

HALL, Stuart; SOVIK, Liv (org.). Da diáspora: Identidades e mediações culturais. Belo Horizonte: Editora UFMG; Brasília: Representação da UNESCO no Brasil, 2003.

JACKS, Nilda. A publicidade vista pela academia: tendências dos anos 9o. In: RAMOS, Roberto (org.). Mídia, Textos e Contextos. Porto Alegre: PUCRS, 2001.

JENSEN, Klaus Bruhn. The social semiotics of mass communication. London: Sage Publications, 1995 .

MARTÍN-BARBERO, Jesús. De los medios a las practicas. In: OROZCO GÓMEZ, Guillermo (coord.), MARTÍN-BARBERO, Jesús, PICCINI, Mabel, GARCIA CANCLINI, Nestor, GARCIA GARZA, Jesus Luis. La comunicación desde las practicas sociales: reflexiones en torno a su investigación. México: Universidad Iberoamericana, 1990.

. Dos meios às mediações: comunicação, cultura e hegemonia. Rio de janeiro: Editora UFRJ, 2003.

MELO, José M. Nem apocalípticos, nem integrados. In: Cadernos IBRACO Simpósio "Propaganda e Sociedade - o positivo e o negativo", nº 2, Agosto/1991, São Paulo, p.1-13. 
SLACK, Jennifer. The theory and method of articulation in cultural studies. In: MORLEY, David e CHEN, Kuan-Hsing (orgs.). Stuart Hall - Critical Dialogues in Cultural Studies. London/New York: Routledge, 1996, p.112-127.

PIEDRAS, Elisa. A articulação da publicidade com o mundo social: a constituição do fluxo publicitário nas práticas de produção e de recepção. Porto Alegre, 2005. Dissertação de Mestrado em Comunicação e Informação Universidade Federal do Rio Grande do Sul.

SOUSA, Anaí Zubik Camargo de. A contribuição de Raymond Williams para a comunicação: os meios como tecnologia e forma cultural. Dissertação (Mestrado em Comunicação) - Faculdade de Comunicação, Pontifícia Universidade Católica do Rio Grande do Sul. Porto Alegre, 2004.

SOUSA, Mauro W. Práticas de recepção mediática como práticas de pertencimento público. Novos Olhares - Revista de Estudos sobre Práticas de Recepção a Produtos Mediáticos ECA/USP. São Paulo, ano 2, n.3, 1999.

SPIGEL, Lynn. Introduction. In: WILLIAMS, Raymond. Television: Technology and Cultural Form. London: Wesleyan University Press, 1992.

WILLIAMS, Raymond. Advertising: the magic system. In: DURING, Simon (org.). The Culture Studies Reader. London: Routledge, 1995, p.320-336.

. Television: Technology and Cultural Form. London: Wesleyan University Press, 1992. 